\title{
Coverage and Access for Americans with Cardiovascular Disease or Risk Factors After the ACA: a Quasi-experimental Study
}

\author{
Ameen Barghi, MPP ${ }^{7}, H$. Torres, MD, MPH${ }^{2}$, N. R. Kressin, $P h D^{3,4}$, and D. McCormick, \\ $\mathrm{MD}, \mathrm{MPH}^{\top}$
}

'Department of Medicine, Cambridge Health Alliance, Harvard Medical School, Cambridge, MA, USA; ${ }^{2}$ Department of Medicine, Massachusetts General Hospital, Harvard Medical School, Boston, MA, USA; ${ }^{3}$ VA Boston Healthcare System, Boston, MA, USA; ${ }^{4}$ Department of General Internal Medicine, Boston University School of Medicine, Boston, MA, USA.

BACKGROUND: Atherosclerotic cardiovascular disease (CVD) is the leading cause of death in the USA. Many with CVD or cardiovascular risk factors (CVRFs) lacked insurance coverage and access to care before enactment of the Affordable Care Act (ACA).

OBJECTIVE: To assess the effect of the ACA on insurance coverage, access to care, and racial/ethnic disparities among non-elderly adults with CVD or CVRFs.

DESIGN: Quasi-experimental policy intervention.

PARTICIPANTS: Nationally representative, noninstitutionalized sample of 1,014,450 adults aged 18 to 64 years with CVD or at least 2 established CVRFs in the pre-ACA (2012-2013) and post-ACA (2015-2016) periods. INTERVENTION: Implementation of ACA provisions on 1 January 2014.

MAIN MEASURES: Insurance coverage, having a checkup, having a personal physician, and not having to forgo a needed physician visit because of cost.

KEY RESULTS: Following ACA implementation, insurance coverage increased by 6.9 percentage points $(95 \%$ CI, 6.6 to 7.2 ), not having to forgo a physician visit increased by 3.6 percentage points (CI, 3.3 to 3.9), having a check-up increased by 2.1 percentage points (CI, 1.8 to 2.6), and having a personal physician increased by 1 percentage point ( 0.6 to 1.3 ); changes were approximately doubled for those with lower incomes $(<\$ 35,000 /$ year $)$. Changes in coverage varied substantially by state and all outcomes improved more in Medicaid expansion states. Although racial/ethnic minorities had greater improvements in some outcomes, approximately $13 \%$ black and 29\% Hispanic adults continued to lack coverage and access to care post-ACA.

CONCLUSION: The ACA increased coverage and access for adults with CVD or multiple CVRFs; substantial gaps remain, particularly for minorities and those in Medicaid non-expansion states.

$\overline{\overline{\text { Prior Presentations Portions of this manuscript were presented in oral }}}$ format at the Society for General Internal Medicine national conference, April 2018.

Electronic supplementary material The online version of this article (https://doi.org/10.1007/s11606-019-05108-1) contains supplementary material, which is available to authorized users.

Received January 22, 2019

Revised April 10, 2019

Accepted May 20, 2019

Published online June 27, 2019
KEY WORDS: cardiovascular; Affordable Care Act; insurance; health care; minority.

J Gen Intern Med 34(9):1797-805

DOI: $10.1007 / \mathrm{s} 11606-019-05108-1$

(c) Society of General Internal Medicine 2019

\section{INTRODUCTION}

Atherosclerotic cardiovascular disease (CVD) is the leading cause of death in the $\mathrm{USA}^{1}$ and over $40 \%$ of Americans are expected to have some form of CVD by 2030. ${ }^{1,2}$ Access to medical care is essential for optimal treatment of CVD and management of cardiovascular risk factors (CVRFs) ${ }^{3-5}$ including high blood pressure, high cholesterol, diabetes, smoking, physical inactivity, and obesity. ${ }^{6}$ For example, people with financial barriers to care are less likely to be screened for $\mathrm{CVRFs}^{7}$ and, following acute myocardial infarction (AMI), are less likely to receive evidence-based CVD treatments. ${ }^{8}$ Similarly, a lack of health insurance has been associated with worse control of $\mathrm{CVRFs}^{9}, 10$ and failure to receive recommended outpatient medications for CVD. ${ }^{11}$ In addition, racial and ethnic minorities - groups with a high prevalence of CVRFs ${ }^{12-}$ 15 _experience greater financial barriers to care, higher rates of uninsurance, ${ }^{16}$ and worse outcomes of CVD treatment. ${ }^{12,} 17,18$

The Patient Protection and Affordable Care Act (ACA) was designed to reduce the number of uninsured Americans and improve access to and affordability of care. ${ }^{19,20}$ The main coverage provisions of the ACA, implemented on January 1, $2014,{ }^{21}$ offered premium and out-of-pocket subsidies to many lower income individuals, a mandate requiring most persons to have health coverage and, at states' discretion, the expansion of Medicaid to adults with family incomes at or below $138 \%$ of the federal poverty level. ${ }^{22}$ Among non-elderly adults nationally, the ACA has resulted in an approximately $40 \%$ decrease in uninsurance ${ }^{23,24}$ and improved access and affordability, ${ }^{23,25}$ with greater gains among racial and ethnic minorities, ${ }^{26,27}$ low-income individuals, ${ }^{24}$ and in states that expanded Medicaid. ${ }^{24,}{ }^{28}$ Because people with CVD and CVRFs are at risk for cardiovascular mortality and have high health care needs, understanding the impact of the ACA on these 
populations has high health policy and public health relevance. However, little is known about the extent to which the ACA or states' Medicaid expansions altered coverage or access to care for Americans with CVD or CVRFs.

We examined the effect of the ACA on non-elderly adults with CVD or CVRFs using a large nationally representative data set. We sought to assess (1) whether the ACA was associated with improvements in insurance coverage and access to care; (2) whether the ACA's optional state Medicaid expansion resulted in increased coverage and access; (3) whether racial and ethnic disparities in these outcomes diminished post-ACA; and (4) the extent to which uninsurance and poor access persist in the post-ACA era.

\section{METHODS}

\section{Data and Study Population}

We analyzed data from the Behavioral Risk Factor Surveillance System (BRFSS), a state-based telephone survey of noninstitutionalized civilians conducted every year by state health departments and the Centers for Disease Control and Prevention. ${ }^{29}$ Using a random-digit dialing survey methodology, the BRFSS asks United States (US) residents of each state questions about health-related risk behaviors, chronic health conditions, demographic characteristics, access to care, and health insurance status. ${ }^{29}$ We analyzed data from 2012 through 2016, the latest year for which BRFSS data was available at the time of the analysis; we excluded data from 2014, the first year of the ACA, as we considered this to be a "washout" period (see Supplement Methods for further details). For this study, the pre-reform period was defined as 2012 and 2013 while the post-reform period was defined as 2015 and 2016.

Our study population was adults aged 18-64 (the target population of the ACA) who reported having history of CVD or two or more CVRFs. We defined individuals as having CVD if they reported having had a history of heart attack, angina, coronary heart disease, or stroke. We defined individuals as having two or more CVRFs (risk factors associated with cardiovascular mortality $)^{30}$ if they reported having two or more of the following: diabetes, being a current cigarette smoker, getting no physical exercise, having a BMI $>25$ (calculated using self-reported weight and height), or being age $>45$ for men or $>55$ for women. We did not include hypertension and hyperlipidemia in the definition of CVRFs in our main analysis because BRFSS data on these conditions was not collected in 2012 or 2016; however, we did include them in a sensitivity analysis (described below).

\section{Study Variables}

We assessed four primary outcomes: having health insurance (at the time of the interview), having had to forgo a physician visit in the last year due to cost (to facilitate comparisons, we report this variable as the inverse, not having to forgo a physician visit due to cost; for brevity, we refer to this as "able to afford a physician visit"), having had a check-up in the last year and having a personal physician. We also used information on demographic characteristics including age, gender, race/ethnicity, marital status, education, employment, and household income. Race/ethnicity was classified as nonHispanic white, non-Hispanic black, Hispanic, and other (see Methods in the Supplement for a full description of all variables).

\section{Statistical Analysis}

For all outcomes, we calculated adjusted and unadjusted percentage point changes on the absolute scale from the pre- to post-ACA periods. We used multivariable logistic regression models to obtain estimates adjusted for marital status, income, sex, employment status, education, and race. Percentage point changes were derived from logit models using the method of Korn and Graubard ${ }^{31}$ to calculate predictive marginal effects at representative values. We assessed pre- to post-ACA changes separately for the overall population, a subset of lower income individuals (family income $<\$ 35,000 /$ year), and residents of each US state. To assess the effect of Medicaid expansion on each outcome, we employed a quasiexperimental difference-in-differences modeling approach ${ }^{32}$ that estimated the adjusted net change in expansion states relative to non-expansion states (the referent group). To assess changes in pre-existing racial and ethnic disparities, we estimated pre- to post-changes in white-black and white-Hispanic disparities in each outcome using the same modeling approach (except race/ethnicity was not included as a model covariate) with whites as the reference group.

We assessed the magnitude of gaps in coverage and access for people with CVD/CVRFs that remain in the post-ACA era for white, black, and Hispanic residents of expansion and nonexpansion states in unadjusted analyses.

We conducted several analyses to assess whether pre-ACA trends were similar in our difference-in-differences analyses ${ }^{33}$ (see Supplement for details).

In addition, we conducted two sensitivity analyses. First, to determine whether inclusion of people with hypertension and hyperlipidemia would have changed our results, we repeated our main analyses using only data from study years in which these diagnoses were elicited, 2013 (pre-ACA) and 2015 (post-ACA). Second, we repeated our analyses separately for individuals with established CVD and those with multiple CVRFs to determine if results could vary between these subgroups.

In all analyses, we applied sampling weights provided by BRFSS to account for differences in probabilities of selection and non-response. All analyses were performed using Stata, version 15 (StatCorp). This study was granted exemption by the Cambridge Health Alliance Institutional Review Board because BRFSS is a publicly available data source. 


\section{RESULTS}

\section{Sample}

For our main study cohort, we analyzed data on 1,014,450 individuals with CVD/CVRFs. Patient characteristics of the study population are shown in Supplement Table 1. Pre- and post-ACA demographics were similar.

\section{Changes in Insurance Coverage and Access Among Adults with CVD/CVRFs, Overall}

For the overall study sample, insurance coverage increased by 6.9 percentage points $(95 \% \mathrm{CI}, 6.6$ to 7.2$)$ in adjusted analysis, reducing the number of people with CVD/CVRFs who were uninsured by 9.8 million (Table 1). All three measures of access to care also improved: ability to afford a physician visit by 3.6 percentage points (95\% CI, 3.3 to 3.9), having an annual checkup by 2.2 percentage points (95\% CI, 1.8 to 2.6), and having a personal physician by 1 percentage point $(95 \%$ CI, 0.6 to 1.3), in adjusted analyses. Among those with incomes $<\$ 35,000 /$ year, these percentage point gains were approximately twice as great (Table 1).

\section{Changes in Outcomes Among Adults with CVD/CVRFs by Medicaid Expansion Status and in Individual States}

Residents of Medicaid expansion states had higher levels of coverage and access in the pre-ACA period and experienced larger increases than residents of non-expansion states in the post-ACA period in unadjusted analyses (Table 2). In adjusted difference-in-differences analyses, residents of Medicaid expansion states experienced net percentage point increases over non-expansion states of 1.7 (95\% CI, 1.0 to 2.3) for insurance coverage, $1.3(95 \%$ CI, 0.6 to 1.9 ) for ability to afford a physician visit, 1.3 (95\% CI, 0.5 to 2.1 ) for having an annual check-up, and 2.8 (95\% CI, 2.0 to 3.5) for having a personal physician. Gains in expansion states among those with incomes $<\$ 35,000 /$ year were, again, approximately twice as great.

Health insurance coverage increased in all states but we observed substantial variation by state and Medicaid expansion status (Table 3 ). The proportion of the population of people with $\mathrm{CVD} / \mathrm{CVRF}$ that remains without insurance in the post-ACA era also varied substantially by state from a low of $6.1 \%$ in Massachusetts to a high of $27.0 \%$ in Texas (Table 3).

\section{Changes in Coverage and Access Among Adults with CVD/CVRFs by Race and Ethnicity}

All measures of coverage and access improved for each racial and ethnic group in unadjusted analyses (Table 4). However, when we examined whether pre-existing racial and ethnic disparities were reduced after the ACA, we observed a mixed picture. In adjusted difference-indifferences analyses, we found a 2.7 percentage point (95\% CI, 2.6 to 2.9 ) increase in coverage among blacks relative to whites and a 5.7 percentage point $(95 \% \mathrm{CI}, 5.4$ to 6.0) increase among Hispanics relative to whites. We also found that the white-black and white-Hispanic gaps in ability to afford a physician visit narrowed slightly (1.0 percentage points (95\% CI, 0.8 to 1.1 ) and 1.5 percentage points (95\% CI, 1.3 to 1.6 ), respectively). For the remaining access measures, we found only small changes of borderline significance.

\section{Remaining Gaps in Coverage and Access Among Adults with CVD/CVRFs, Overall and by Medicaid Expansion Status, and Race and Ethnicity}

Despite gains in the post-ACA era, large proportions of people with CVD/CVRFs continue to lack coverage and access. For example, nationally, $14.5 \%$ (Table 1) or 20.6 million people with CVD/CVRFs continued to lack insurance coverage after ACA implementation. In addition, $12.9 \%$ of black and $28.7 \%$ of Hispanic people lacked coverage in the post-ACA period (Table 4). We found that the persistent lack of coverage and access was particularly great for minorities in non-expansion states (Fig. 1). For example, among Hispanic people with CVD/CVRFs in non-expansion states post-ACA, $42 \%$ continued to lack insurance coverage, $25 \%$ could not afford a physician visit, $40 \%$ did not have a check-up in the last year, and $48 \%$ did not have a personal physician.

\section{Pre-ACA Placebo Time Trend and Sensitivity Analyses}

Our placebo analyses comparing pre-ACA trends (2012 to 2013 ) in outcomes between Medicaid expansion and nonexpansion states demonstrated that trends were parallel (Supplement Table 2). The placebo analysis of pre-ACA trends according to race/ethnicity showed a mixed picture with pre-ACA increases in coverage and ability to afford a physician among black and Hispanic relative to white individuals and an increase in having a personal physician among white relative to black and Hispanic individuals; trends were parallel for having a check-up in the past year (Supplement Table 3). All noted pre-trend differences were small (0.2-0.7 percentage points), however. Sensitivity analyses that included diagnoses of hypertension and hyperlipidemia as CVRFs (using data only from 2013 and 2015) produced results largely similar to the main analysis (Supplement Table 4). In sensitivity analyses examining the CVD and CVRF populations separately, we found similar changes in insurance coverage for the CVD and CVRF cohorts overall and by Medicaid expansion status (Supplement Table 5). 
Table 1 Effect of the ACA on Changes in Health Insurance Coverage and Access to Care Among US Adults with CVD or Multiple CVRFs

\begin{tabular}{|c|c|c|c|c|c|}
\hline Outcome & $\begin{array}{l}\text { Pre-ACA } \\
\text { unadjusted } \\
\text { prevalence }\end{array}$ & $\begin{array}{l}\text { Post-ACA } \\
\text { unadjusted } \\
\text { prevalence }\end{array}$ & $\begin{array}{l}\text { Unadjusted } \\
\text { percentage point } \\
\text { change }\end{array}$ & $\begin{array}{l}\text { Adjusted percentage } \\
\text { point change* }(95 \% \\
\text { CI) }\end{array}$ & $\begin{array}{l}\text { Number newly achieving } \\
\text { outcome post-ACA (mil- } \\
\text { lions) }\end{array}$ \\
\hline \multicolumn{6}{|l|}{ All income levels } \\
\hline $\begin{array}{l}\text { Health } \\
\text { insurance }\end{array}$ & 78.8 & 85.5 & 6.7 & $6.9(6.6$ to 7.2$)$ & 9.8 \\
\hline $\begin{array}{l}\text { Able to afford } \\
\text { physician visit }\end{array}$ & 81.8 & 85.3 & 3.5 & $3.6(3.3$ to 3.9$)$ & 5.1 \\
\hline $\begin{array}{l}\text { Had annual } \\
\text { check-up }\end{array}$ & 65.1 & 67.2 & 2.1 & $2.2(1.8$ to 2.6$)$ & 2.4 \\
\hline $\begin{array}{l}\text { Had personal } \\
\text { physician }\end{array}$ & 73.9 & 74.7 & 0.8 & $1.0(0.6$ to 1.3$)$ & 1.2 \\
\hline \multicolumn{6}{|c|}{ Lower income $(<\$ 35,000 /$ year $)$} \\
\hline $\begin{array}{l}\text { Health } \\
\text { insurance }\end{array}$ & 61.3 & 73.8 & 12.5 & $12.5(11.8$ to 13.1$)$ & 4.9 \\
\hline $\begin{array}{l}\text { Able to afford } \\
\text { physician visit }\end{array}$ & 67.7 & 74.5 & 6.8 & $6.8(6.1$ to 7.4$)$ & 2.7 \\
\hline $\begin{array}{l}\text { Had annual } \\
\text { check-up }\end{array}$ & 59.3 & 63.8 & 4.5 & 4.5 (3.8 to 5.2$)$ & 1.5 \\
\hline $\begin{array}{l}\text { Had personal } \\
\text { physician }\end{array}$ & 62.5 & 65.9 & 3.3 & $3.3(2.6$ to 4.0$)$ & 1.1 \\
\hline
\end{tabular}

*Adjusted for marital status, income, sex, employment status, education, time period (pre-ACA vs. post-ACA), and race

ACA, Affordable Care Act; CVD, cardiovascular disease; CVRFs, cardiovascular risk factors

\section{DISCUSSION}

In this nationally representative cohort of adults with CVD/ CVRFs, the ACA was associated with improvements in insurance coverage and measures of access to care, particularly among those with lower incomes. Residents of Medicaid expansion states experienced greater improvements for each outcome than residents of non-expansion states, again, with much larger effects seen among those with lower incomes. The ACA was also associated with a narrowing of racial and ethnic disparities in insurance coverage and ability to afford a physician visit. Despite these overall improvements, the proportion of adults with $\mathrm{CVD} / \mathrm{CVRFs}$ who lack coverage and experience barriers to care in the post-ACA era remains substantial, particularly among residents of Medicaid non-expansion states and among racial and ethnic minorities.

Prior studies have shown that insurance coverage and access to care improved among people with multiple chronic conditions, ${ }^{34}$ diabetes, ${ }^{35}$ and cigarette smokers. ${ }^{36}$ Only one prior study (which was not peer reviewed) has examined the effect of the ACA on people with CVRFs, ${ }^{37}$ but was limited to the first year of the post-ACA period. It

Table 2 Effect of the ACA's Medicaid Expansion on Changes in Health Insurance Coverage and Access to Care Among Adults with CVD or Multiple CVRFs

\begin{tabular}{|c|c|c|c|c|c|c|c|}
\hline \multirow[t]{2}{*}{ Outcome } & \multicolumn{3}{|c|}{ Medicaid expansion states } & \multicolumn{3}{|c|}{ Medicaid non-expansion states } & \multirow{2}{*}{$\begin{array}{l}\begin{array}{l}\text { Adjusted difference-in- } \\
\text { differences* }(95 \% \text { CI })\end{array} \\
\begin{array}{l}\text { Percentage point } \\
\text { change }\end{array}\end{array}$} \\
\hline & Pre-ACA & Post-ACA & $\begin{array}{l}\text { Unadjusted } \\
\text { percentage } \\
\text { point change }\end{array}$ & Pre-ACA & Post-ACA & $\begin{array}{l}\text { Unadjusted } \\
\text { percentage } \\
\text { point change }\end{array}$ & \\
\hline \multicolumn{8}{|l|}{ All incomes } \\
\hline Health insurance & 81.3 & 88.7 & 7.4 & 76.0 & 81.0 & 5.0 & $1.7(1.0$ to 2.3$)$ \\
\hline Able to afford physician visit & 83.4 & 87.3 & 3.9 & 79.9 & 82.5 & 2.5 & $1.3(0.6$ to 1.9$)$ \\
\hline Had annual check-up & 64.7 & 67.4 & 2.7 & 65.5 & 66.8 & 1.3 & $1.3(0.5$ to 2.1$)$ \\
\hline Had personal physician & 75.2 & 77.3 & 2.2 & 72.4 & 70.9 & -1.5 & $2.8(2.0$ to 3.5$)$ \\
\hline \multicolumn{8}{|l|}{ Lower income $(<\$ 35,000 /$ year $)$} \\
\hline Health insurance & 64.9 & 79.3 & 14.4 & 57.6 & 66.8 & 9.2 & $4.3(3$ to 5.6$)$ \\
\hline Able afford physician visit & 70.2 & 78.3 & 8.1 & 65.2 & 69.7 & 4.5 & $3.4(2.1$ to 4.7$)$ \\
\hline Had annual check-up & 59.5 & 64.9 & 5.4 & 59.2 & 62.4 & 3.2 & $2.3(0.9$ to 3.7$)$ \\
\hline Had personal physician & 63.5 & 68.7 & 5.2 & 61.5 & 62.3 & 0.8 & $3.7(2.3$ to 5.0$)$ \\
\hline
\end{tabular}

*Adjusted for marital status, income, sex, employment status, education, time period (pre-ACA vs. post-ACA), and race. The difference-in-differences estimate represents the change in Medicaid expansion states relative to the change in non-expansion states (referent). A positive value indicates a greater improvement (gain) in the outcome in expansion states relative to non-expansion states

ACA, Affordable Care Act; CVD, cardiovascular disease; CVRFs, cardiovascular risk factors 
Table 3 Effect of the ACA's Medicaid Expansion on Changes in Health Insurance Coverage and Access to Care Among Adults with CVD or Multiple CVRFs Among US States

\begin{tabular}{|c|c|c|c|c|c|}
\hline \multirow[t]{2}{*}{$\begin{array}{l}\text { Current state Medicaid } \\
\text { expansion status }\end{array}$} & \multicolumn{2}{|c|}{ Unadjusted prevalence of insurance coverage $(\%)$} & \multicolumn{2}{|c|}{$\begin{array}{l}\text { Change in insurance coverage } \\
\text { (percentage points) }\end{array}$} & \multirow{2}{*}{$\begin{array}{l}\text { Prevalence of } \\
\text { uninsurance } \\
\text { post-ACA }(\%)\end{array}$} \\
\hline & Before ACA (95\% CI) & After ACA (95\% CI) & Unadjusted & Adjusted* (95\% CI) & \\
\hline \multicolumn{6}{|l|}{ Expansion states } \\
\hline Alaska & $79.8(78.2$ to 81.3$)$ & $86.2(84.1$ to 88.0$)$ & 6.4 & $5.3(2.9$ to 7.7$)$ & 13.8 \\
\hline Arkansas & 71.7 (70.0 to 73.4$)$ & $86.3(84.5$ to 88.0$)$ & 14.6 & $13.9(11.7$ to 16$)$ & 13.7 \\
\hline Arizona & $76.0(73.9$ to 78.0$)$ & $83.0(81.7$ to 84.3$)$ & 7.0 & $4.7(2.4$ to 7.1$)$ & 17 \\
\hline California & 77.4 (76.5 to 78.3$)$ & $86.8(86.1$ to 87.5$)$ & 9.4 & $8.6(7.4$ to 9.7$)$ & 13.2 \\
\hline Colorado & 79.9 (79.0 to 80.8$)$ & 87.3 (86.5 to 88.0$)$ & 7.4 & $6.2(5.1$ to 7.3$)$ & 12.7 \\
\hline Connecticut & $87.5(86.4$ to 88.4$)$ & $91.4(90.6$ to 92.1$)$ & 3.9 & $3.9(2.7$ to 5.1$)$ & 8.6 \\
\hline Delaware & $86.3(84.9$ to 87.5$)$ & $89.6(88.2$ to 90.7$)$ & 3.3 & $4.1(2.3$ to 5.8$)$ & 10.4 \\
\hline DC & $90.6(89.1$ to 91.9$)$ & $93.8(92.4$ to 95.0$)$ & 3.2 & $3.0(1.1$ to 4.9$)$ & 6.2 \\
\hline Hawaii & $89.1(88.1$ to 90.1$)$ & 91.5 (90.6 to 92.4$)$ & 2.4 & $2.3(1.0$ to 3.7$)$ & 8.5 \\
\hline Illinois & $80.8(79.2$ to 82.3$)$ & $88.8(87.7$ to 89.9$)$ & 8.0 & $7.2(5.6$ to 8.9$)$ & 11.2 \\
\hline Iowa & $87.0(86.0$ to 88.0$)$ & $92.2(91.3$ to 93.1$)$ & 4.7 & $4.1(2.8$ to 5.3$)$ & 7.8 \\
\hline Kentucky & $79.2(78.1$ to 80.3$)$ & 92.5 (91.6 to 93.3$)$ & 13.3 & $13.5(11.9$ to 15$)$ & 7.5 \\
\hline Maryland & $84.4(83.3$ to 85.4$)$ & $89.8(88.7$ to 90.9$)$ & 5.5 & $5.3(3.9$ to 6.8$)$ & 10.2 \\
\hline Massachusetts & 93.1 (92.6 to 93.7$)$ & 93.9 (93.2 to 94.5$)$ & 0.8 & $0.5(-0.3$ to 1.6$)$ & 6.1 \\
\hline Michigan & $83.9(82.9$ to 84.8$)$ & $89.3(88.5$ to 90.1$)$ & 5.4 & $5.0(3.8$ to 6.3$)$ & 10.7 \\
\hline Minnesota & $87.0(86.1$ to 87.8$)$ & 92.7 (92.2 to 93.2$)$ & 5.7 & $4.7(3.7$ to 5.7$)$ & 7.3 \\
\hline Nevada & 72.7 (70.7 to 74.7$)$ & $82.9(81.0$ to 84.6$)$ & 10.2 & $9.8(7.3$ to 12.3$)$ & 17.1 \\
\hline New Hampshire & $85.4(84.2$ to 86.5$)$ & 92.0 (91.0 to 92.9$)$ & 6.5 & $5.7(4.2$ to 7.2$)$ & 8.0 \\
\hline New Jersey & $81.0(80.1$ to 81.8$)$ & 86.7 (85.6 to 87.8$)$ & 5.8 & $5.7(4.4$ to 7.1$)$ & 13.3 \\
\hline New Mexico & $74.4(73.2$ to 75.6$)$ & $87.4(86.1$ to 88.6$)$ & 13 & $12.4(10.8$ to 14.1$)$ & 12.6 \\
\hline New York & $82.7(81.5$ to 83.8$)$ & $88.0(87.2$ to 88.7$)$ & 5.3 & $5.1(3.7$ to 6.4$)$ & 12.0 \\
\hline North Dakota & $86.6(85.4$ to 87.7$)$ & 90.9 (89.8 to 91.9$)$ & 4.3 & $4.2(2.6$ to 5.7$)$ & 9.1 \\
\hline Ohio & $83.6(82.6$ to 84.5$)$ & 91.0 (90.0 to 91.8$)$ & 7.4 & $6.6(5.3$ to 7.9$)$ & 9.0 \\
\hline Oregon & 77.2 (75.6 to 78.6$)$ & 89.2 (88.1 to 90.2$)$ & 12 & $11.2(9.3$ to 13.0$)$ & 10.8 \\
\hline Rhode Island & $82.0(80.6$ to 83.3$)$ & $90.5(89.2$ to 91.7$)$ & 8.5 & $9.2(7.4$ to 11.0$)$ & 9.5 \\
\hline Vermont & 88.7 (87.6 to 89.7$)$ & $93.6(92.8$ to 94.3$)$ & 4.9 & $4.3(2.9$ to 5.6$)$ & 6.4 \\
\hline Washington & 79.8 (78.8 to 80.7$)$ & $88.5(87.7$ to 89.2$)$ & 8.7 & $7.9(6.8$ to 9.0$)$ & 11.5 \\
\hline West Virginia & $77.4(76.1$ to 78.7$)$ & 91.0 (90.1 to 91.8$)$ & 13.5 & $13.7(12.2$ to 15.3$)$ & 9.0 \\
\hline \multicolumn{6}{|l|}{ Non-expansion states } \\
\hline Alabama & $78.9(77.4$ to 80.2$)$ & $84.5(83.3$ to 85.6$)$ & 5.6 & $5.2(3.5$ to 6.9$)$ & 15.5 \\
\hline Florida & $72.1(70.7$ to 73.4$)$ & 78.9 (77.8 to 79.9$)$ & 6.8 & $4.9(4.5$ to 7.8$)$ & 21.1 \\
\hline Georgia & $73.5(72.1$ to 74.8$)$ & $80.2(78.7$ to 81.6$)$ & 6.7 & $5.8(3.9$ to 7.7$)$ & 19.8 \\
\hline Idaho & $76.9(75.2$ to 78.6$)$ & $82.3(80.8$ to 83.7$)$ & 5.4 & $4.2(2.1$ to 6.2$)$ & 17.7 \\
\hline Indiana & $79.2(78.1$ to 80.3$)$ & $86.6(85.4$ to 87.7$)$ & 7.4 & $6.5(5.0$ to 8.0$)$ & 13.4 \\
\hline Kansas & 80.1 (79.3 to 80.9$)$ & $84.8(84.0$ to 85.5$)$ & 4.7 & $3.7(2.7$ to 4.7$)$ & 15.2 \\
\hline Louisiana & 75.2 (73.6 to 76.8$)$ & $82.8(81.2$ to 84.3$)$ & 7.6 & $7.0(4.8$ to 9.2$)$ & 17.2 \\
\hline Maine & $85.2(84.2$ to 86.2$)$ & 89.5 (88.4 to 90.4$)$ & 4.2 & $3.5(2.1$ to 4.9$)$ & 10.5 \\
\hline Mississippi & 73.2 (71.8 to 74.5$)$ & 80.4 (78.9 to 81.8$)$ & 7.2 & $6.3(4.4$ to 8.3$)$ & 19.6 \\
\hline Missouri & $81.3(80.0$ to 82.6$)$ & 86.8 (85.6 to 87.9$)$ & 5.5 & $4.3(2.6$ to 6.0$)$ & 13.2 \\
\hline Montana & 79.1 (78.8 to 80.2$)$ & 87.7 (86.4 to 88.9$)$ & 8.6 & $7.2(5.5$ to 8.9$)$ & 12.3 \\
\hline Nebraska & $82.9(82.1$ to 83.8$)$ & $86.0(85.1$ to 86.8$)$ & 3.0 & $2.9(1.8$ to 4.0$)$ & 14.0 \\
\hline North Carolina & $75.6(74.5$ to 76.6$)$ & $82.1(81.0$ to 83.1$)$ & 6.5 & $5.5(4.1$ to 6.9$)$ & 17.9 \\
\hline Oklahoma & 78.5 (77.3 to 79.6$)$ & $82.7(81.4$ to 84.0$)$ & 4.3 & $3.9(2.3$ to 5.6$)$ & 17.3 \\
\hline Pennsylvania & $85.1(84.2$ to 85.9$)$ & $91.1(90.1$ to 92.1$)$ & 6.1 & $5.0(3.7$ to 6.3$)$ & 8.9 \\
\hline South Carolina & 75.9 (74.8 to 77.0$)$ & $83.5(82.5$ to 84.4$)$ & 7.6 & $6.3(4.9$ to 7.7$)$ & 16.5 \\
\hline South Dakota & $86.4(85.1$ to 87.6$)$ & $90.5(89.2$ to 91.7$)$ & 4.1 & $3.1(1.4$ to 4.9$)$ & 9.5 \\
\hline Tennessee & $79.3(77.9$ to 80.6$)$ & $85.3(83.9$ to 86.6$)$ & 6.0 & $5.7(3.7$ to 7.6$)$ & 14.7 \\
\hline Texas & $66.3(65.0$ to 67.6$)$ & 73.0 (71.6 to 74.3$)$ & 6.7 & $6.1(4.4$ to 7.7$)$ & 27.0 \\
\hline Utah & $80.8(79.9$ to 81.6$)$ & 87.1 (86.3 to 87.9$)$ & 6.3 & $5.2(4.2$ to 6.3$)$ & 12.9 \\
\hline Virginia & $82.0(80.8$ to 83.1$)$ & $87.1(86.2$ to 88.0$)$ & 5.1 & $4.3(3.0$ to 5.7$)$ & 12.9 \\
\hline Wisconsin & $86.3(85.0$ to 87.5$)$ & $90.4(89.2$ to 91.5$)$ & 4.1 & $4.2(2.5$ to 5.9$)$ & 9.6 \\
\hline Wyoming & $77.1(75.5$ to 78.7$)$ & 83.3 (81.6 to 84.9$)$ & 6.2 & 5.9 (3.7 to 8.0$)$ & 16.7 \\
\hline
\end{tabular}

*Adjusted for marital status, income, sex, employment status, education, and race

ACA, Affordable Care Act; CVD, cardiovascular disease; CVRFs, cardiovascular risk factors

found a $4.4 \%$ decline in uninsurance, an effect that is smaller than but consistent with our findings. No studies have assessed the effect of the ACA on people with established CVD.
Our finding that the ACA improved insurance coverage and access to care for people with CVD/CVRFs, particularly those with lower incomes, is important since individuals with CVD/ CVRFs are at elevated risk of mortality and typically 
Table 4 Effect of the ACA on Changes in Health Insurance Coverage and Access to Care Among Adults with CVD or Multiple CVRFs According to Race/Ethnicity

\begin{tabular}{llllll}
\hline \hline Outcome & $\begin{array}{l}\text { Pre-ACA unadjusted } \\
\text { prevalence }\end{array}$ & $\begin{array}{l}\text { Post-ACA unadjusted } \\
\text { prevalence }\end{array}$ & $\begin{array}{l}\text { Unadjusted percentage } \\
\text { point change }\end{array}$ & $\begin{array}{l}\text { Unadjusted difference- } \\
\text { in-differences }\end{array}$ & $\begin{array}{l}\text { Adjusted difference in } \\
\text { differences* }\end{array}$ \\
\hline $\begin{array}{l}\text { (95\% } \\
\text { CI) }\end{array}$
\end{tabular}

*Adjusted for marital status, income, sex, employment status, and education. A positive value indicates a greater improvement (gain) in the outcome for black or Hispanic people compared with white people; a negative value indicates a worsening (decline) in the outcome for black or Hispanic people compared with white people

ACA, Affordable Care Act; CVD, cardiovascular disease; CVRFs, cardiovascular risk factors

have high health care needs. When patients with CVD/ CVRFs are uninsured or face access barriers, they are more likely to experience a wide range of adverse outcomes. For example, the uninsured and those reporting financial barriers to care are more likely to delay hospital presentation for $\mathrm{AMI}^{38}$ and during the first year of recovery after AMI, those reporting financial barriers are more likely to have lower quality of life scores, higher cardiac rehospitalization rates, and more angina. ${ }^{39}$ In addition, a lack of insurance coverage ${ }^{11}$ and low income ${ }^{8}$ are also both associated with failure to receive guideline-recommended outpatient medications in patients with established coronary artery disease.

Our finding that coverage and access improved to a greater degree in Medicaid expansion states-with a particularly large increase in coverage of 14.4 percentage points among lower income adults in expansion states - indicates that the benefits of the Medicaid expansion observed in previous studies of all non-elderly adults ${ }^{23}$ extend to people with CVD/CVRFs and are substantial. Similarly, our finding that pre-existing racial and ethnic disparities among adults with CVD or CVRFs narrowed is also important. Socioeconomic and racial and ethnic disparities in cardiovascular disease prevalence and outcomes have been recognized for decades ${ }^{12,13}$ and elimination of these disparities has been a key goal of clinicians, policy experts, and the federal government. ${ }^{40,41}$

The gains we observed, however, should be viewed in context. While we found that 9.8 million people with $\mathrm{CVD} / \mathrm{CVRF}$ s gained coverage, 20.6 million continue to lack insurance coverage, including strikingly large proportions of racial and ethnic minorities and residents of
Medicaid non-expansion states. There are likely multiple reasons why the ACA did not close these gaps more than it did, including states' decisions to not expand Medicaid, ineligibility of millions of Hispanic persons for coverage due to their immigration status, perceived unaffordability of plans offered through marketplaces, ${ }^{42}$ and persistence of out-of-pocket expenses that are high relative to income. ${ }^{25}$

Our study has several limitations. First, our analysis of the overall pre-post ACA changes in outcomes did not employ a control group, as all states were affected by the ACA. Thus, these findings could have been influenced by unmeasured secular trends in factors affecting our outcomes such as, potentially, improvements in the economy or employment-related insurance gains not captured by our controlling for unemployment in our models. However, our analyses of the effects of the Medicaid expansion and changes in racial and ethnic disparities used a more robust study design (quasi-experimental difference-in-differences analysis) and were thus less susceptible to the influence of secular trends. Second, for three outcomes, we found pre-ACA trend differences; however, these were small and thus likely did not have a substantial impact on our results. Third, while we were not able to include individuals with hypertension and hyperlipidemia in our main analysis, our sensitivity analysis that included these CVRFs showed effect sizes that were very similar to our main results. Fourth, our study population combines two subpopulations with higher (CVD) and lower (CVRFs) underlying risks of cardiovascular mortality and of needing health care services. However, while modifiable CVRFs such as tobacco use, 


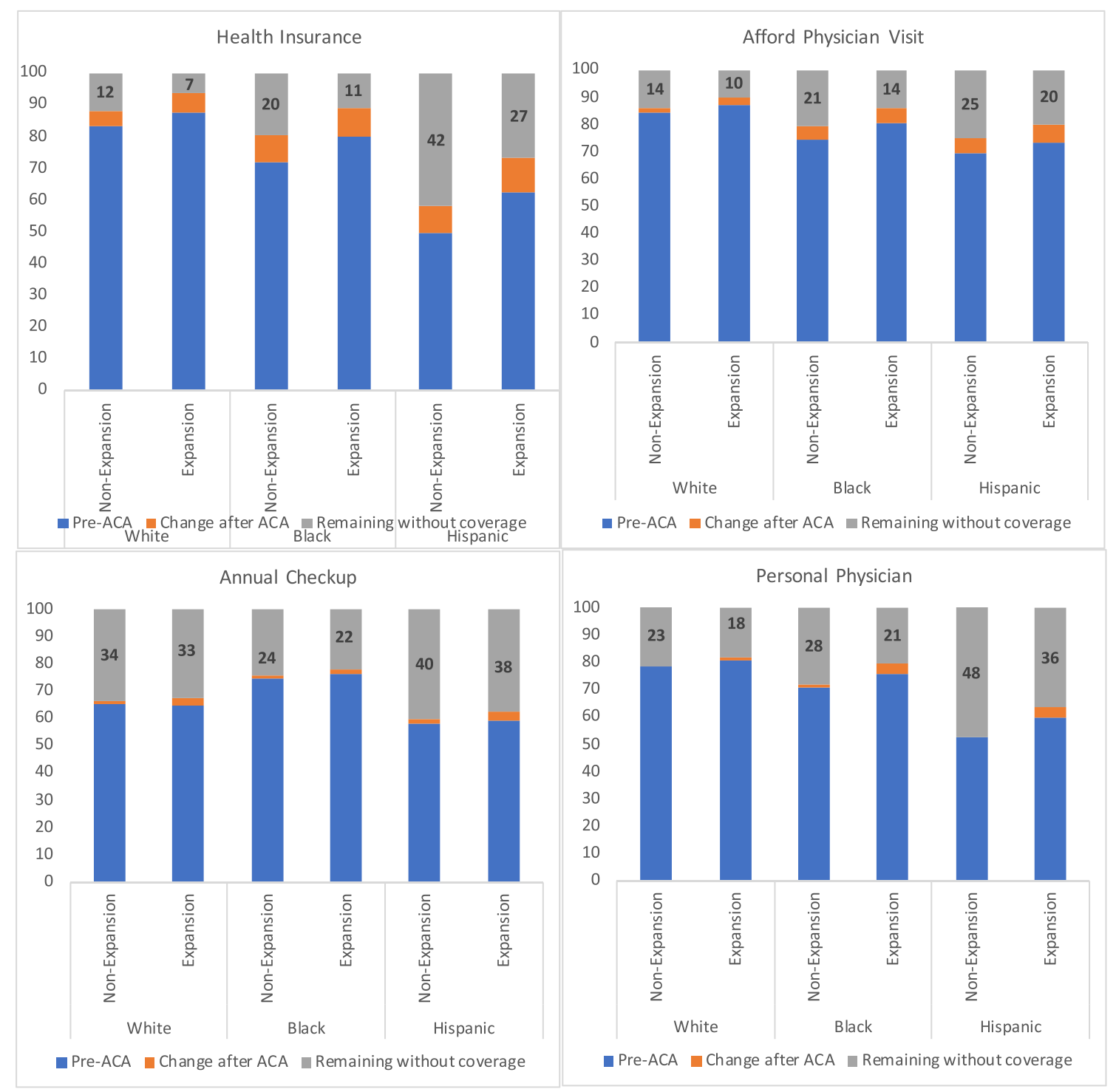

Figure 1 Unadjusted percentage of respondents reporting health insurance and access outcomes, showing the pre-ACA percentage, change after ACA implementation, and percentage remaining without coverage or access in Medicaid expansion and non-expansion states.

overweight/obesity, and physical inactivity carry lower risks than established CVD, these CVRFs alone account for approximately $40 \%$ of all US deaths. ${ }^{6}$ In addition, our sensitivity analyses that examined CVD and CVRF populations separately found comparable effect sizes. Fifth, the BRFSS is only conducted in English and Spanish which may limit the applicability of our findings to populations speaking these languages. Lastly, the BRFSS is a telephone survey and not all people eligible to participate could be reached (response rate for the study years varied from 45.2 to $47.2 \%$ ) potentially leading to nonresponse bias. However, the use of BRFSS-provided survey weights to account for non-response likely reduced this potential effect.

\section{CONCLUSION}

Our findings have several implications relating to the ongoing health insurance expansion debate. First, the gains in access and coverage we found represent significant progress and likely have substantial health ramifications for people with CVD/CVRFs. Second, states' failure to expand Medicaid has likely resulted in a substantial missed opportunity to improve health outcomes in people with CVD/CVRFs, particularly because they comprise larger shares of the populations in most non-expansion states ${ }^{43}$ Third, repealing all or significant parts of the ACA without a comparable alternative would risk the loss of coverage and access to care for millions of Americans with CVD/CVRFs. This is a realistic concern since 
several changes that could increase uninsurance have already recently been adopted, including repeal of the ACA's individual mandate, cuts in advertising and outreach during marketplace open enrollment periods, and the imposition of Medicaid work requirements in some states. ${ }^{44}$ Finally, even if the ACA remains in place, many patients with $\mathrm{CVD} / \mathrm{CVRF}$ s will continue to be uninsured and without access. ${ }^{45}$ In order to substantially improve outcomes for Americans with CVD/ CVRFs, a much more comprehensive health reform than the ACA would be required.

Corresponding Author: Ameen Barghi, MPP; Department of Medicine, Cambridge Health Alliance, Harvard Medical School, Cambridge, MA, USA (e-mail: Ameen_barghi@hms.harvard.edu).

Author Contributions All authors contributed to the project design, data analysis, and manuscript write-up processes.

Funding This study received financial support from the National Heart, Lung and Blood Institute (NIH), grant number 1UO1HL10534201 (Drs. Kressin and McCormick).

\section{Compliance with Ethical Standards:}

Conflict of Interest: The authors declare that they do not have a conflict of interest.

\section{REFERENCES}

1. Benjamin EJ, Blaha MJ, Chiuve SE, et al. Heart Disease and Stroke Statistics-2017 Update: A Report From the American Heart Association. Circulation. 2017;135(10):e146-e603.

2. Heidenreich PA, Trogdon JG, Khavjou OA, et al. Forecasting the future of cardiovascular disease in the United States: a policy statement from the American Heart Association. Circulation. 2011;123(8):933-944.

3. Rao Kondapally Seshasai S, Kaptoge S, Thompson A, et al. Diabetes mellitus, fasting glucose, and risk of cause-specific death. N Engl J Med. 2011;364(9):829-841.

4. Jha P, Ramasundarahettige C, Landsman V, et al. 21st-century hazards of smoking and benefits of cessation in the United States. N Engl J Med. 2013;368(4):341-350.

5. Prospective Studies C, Lewington S, Whitlock G, et al. Blood cholesterol and vascular mortality by age, sex, and blood pressure: a meta-analysis of individual data from 61 prospective studies with 55,000 vascular deaths. Lancet. 2007;370(9602):1829-1839.

6. Danaei G, Ding EL, Mozaffarian D, et al. The preventable causes of death in the United States: comparative risk assessment of dietary, lifestyle, and metabolic risk factors. PLoS Med. 2009;6(4):e1000058.

7. Parikh PB, Yang $\mathbf{J}$, Leigh $\mathbf{S}$, et al. The impact of financial barriers on access to care, quality of care and vascular morbidity among patients with diabetes and coronary heart disease. J Gen Intern Med. 2014;29(1):76-81.

8. Hanley GE, Morgan S, Reid RJ. Income-related inequity in initiation of evidence-based therapies among patients with acute myocardial infarction. J Gen Intern Med. 2011;26(11):1329-1335.

9. Wilper AP, Woolhandler S, Lasser KE, McCormick D, Bor DH, Himmelstein DU. Hypertension, diabetes, and elevated cholesterol among insured and uninsured U.S. adults. Health Aff (Millwood). 2009;28(6):w1151-1159.

10. McClurkin MA, Yingling LR, Ayers C, et al. Health Insurance Status as a Barrier to Ideal Cardiovascular Health for U.S. Adults: Data from the National Health and Nutrition Examination Survey (NHANES). PLoS One. 2015; 10(11):e0141534.

11. Smolderen KG, Spertus JA, Tang F, et al. Treatment differences by health insurance among outpatients with coronary artery disease: insights from the national cardiovascular data registry. J Am Coll Cardiol. 2013;61(10):1069-1075.

12. Mensah GA, Mokdad AH, Ford ES, Greenlund KJ, Croft JB. State of disparities in cardiovascular health in the United States. Circulation. 2005;111(10):1233-1241.

13. Pool LR, Ning H, Lloyd-Jones DM, Allen NB. Trends in Racial/Ethnic Disparities in Cardiovascular Health Among US Adults From 1999-2012. J Am Heart Assoc. 2017;6(9).

14. Caleyachetty R, Echouffo-Tcheugui JB, Muennig P, Zhu W, Muntner P, Shimbo D. Association between cumulative social risk and ideal cardiovascular health in US adults: NHANES 1999-2006. Int J Cardiol. 2015; 191:296-300.

15. Pilkerton CS, Singh SS, Bias TK, Frisbee SJ. Changes in Cardiovascular Health in the United States, 2003-2011. J Am Heart Assoc. 2015;4(9):e001650.

16. 2014 National HealthCare Quality and Disparities Report. Agency for Healthcare Research and Quality. Available at http://www.ahrq.gov/research/findings/nhqrdr/nhqdr14/2014nhqdr.pdf. Accessed 26 April 2019.

17. Leigh JA, Alvarez M, Rodriguez CJ. Ethnic Minorities and Coronary Heart Disease: an Update and Future Directions. Curr Atheroscler Rep. 2016;18(2):9.

18. Havranek EP, Mujahid MS, Barr DA, et al. Social Determinants of Risk and Outcomes for Cardiovascular Disease: A Scientific Statement From the American Heart Association. Circulation. 2015;132(9):873-898.

19. U.S. Department of Health and Human Services. Strategic goal 1: strengthen health care. 2016. Available at https://www.hhs.gov/about/ strategic-plan/strategic-goal-1/index.html. Accessed 26 April 2019.

20. Clemans-Cope L, Kenney GM, Buettgens M, Carroll C, Blavin F. The Affordable Care Act's coverage expansions will reduce differences in uninsurance rates by race and ethnicity. Health Aff (Millwood). 2012;31(5):920-930.

21. The Henry J. Kaiser Family Foundation. Health reform implementation timeline. 2016. Available at http://kff.org/interactive/implementationtimeline. Accessed 26 April 2019.

22. Patient Protection and Affordable Care Act. 111th Congress. Public Law 148. 2010. Available at: https://www.gpo.gov/fdsys/pkg/PLAW111 publ148/html/PLAW-111publ148.htm. Accessed 26 April 2019.

23. Long SK, Bart L, Karpman M, Shartzer A, Zuckerman S. Sustained Gains In Coverage, Access, And Affordability Under The ACA: A 2017 Update. Health Aff (Millwood). 2017;36(9):1656-1662.

24. Cohen RA, Zammitti EP, Martinez ME. Health Insurance Coverage: Early Release of Estimates from the National Health Interview Survey, 2017. National Center for Health Statistics. 2018. Available at : https:// www.cdc.gov/nchs/data/nhis/earlyrelease/insur201711.pdf. Accessed 26 April 2019.

25. Goldman AL, Woolhandler S, Himmelstein DU, Bor DH, McCormick D. Out-of-Pocket Spending and Premium Contributions After Implementation of the Affordable Care Act. JAMA Intern Med. 2018;178(3):347355.

26. McMorrow S, Long SK, Kenney GM, Anderson N. Uninsurance Disparities Have Narrowed For Black And Hispanic Adults Under The Affordable Care Act. Health Aff (Millwood). 2015;34(10): 1774-1778.

27. Buchmueller TC, Levinson ZM, Levy HG, Wolfe BL. Effect of the Affordable Care Act on Racial and Ethnic Disparities in Health Insurance Coverage. Am J Public Health. 2016;106(8):1416-1421.

28. Miller S, Wherry LR. Health and Access to Care during the First 2 Years of the ACA Medicaid Expansions. N Engl J Med. 2017;376(10):947-956.

29. Centers for Disease Control and Prevention. Behavioral Risk Factor Surveillance System (BRFSS). 2018. Available at: https://www.cdc.gov/ brfss/index.html.. Accessed 26 April 2019.

30. Patel SA, Winkel M, Ali MK, Narayan KM, Mehta NK. Cardiovascular mortality associated with 5 leading risk factors: national and state preventable fractions estimated from survey data. Ann Intern Med. 2015;163(4):245-253.

31. Graubard BI, Korn EL. Predictive margins with survey data. Biometrics. 1999;55(2):652-659.

32. Dimick JB, Ryan AM. Methods for evaluating changes in health care policy: the difference-in-differences approach. JAMA. 2014;312(22):2401-2402.

33. Calonico SCM, Farrell M, Titiunik R. Regression Discontinuity Designs Using Covariates. Ann Arbor: University of Michigan; 2016.

34. Torres H, Poorman E, Tadepalli U, et al. Coverage and Access for Americans With Chronic Disease Under the Affordable Care Act: A QuasiExperimental Study. Ann Intern Med. 2017;166(7):472-479.

35. Casagrande SS, McEwen LN, Herman WH. Changes in Health Insurance Coverage Under the Affordable Care Act: A National Sample of U.S. 
Adults With Diabetes, 2009 and 2016. Diabetes Care. 2018;41(5):956962.

36. Koma JW, Donohue JM, Barry CL, Huskamp HA, Jarlenski M. Medicaid Coverage Expansions and Cigarette Smoking Cessation Among Low-income Adults. Med Care. 2017;55(12):1023-1029.

37. Ku L,Steinmetz E, Bruen B, Bysshe T. Effects of the Affordable Care Act on Health Insurance Coverage of Americans at Risk for Cardiovascular disease. Report. Milken Institute School of Public Health. 2016. Available at: http://www.heart.org/idc/groups/heart-public/@wcm/@adv/documents/downloadable/ucm_480864.pdf. Accessed 26 April 2019.

38. Smolderen KG, Spertus JA, Nallamothu BK, et al. Health care insurance, financial concerns in accessing care, and delays to hospital presentation in acute myocardial infarction. JAMA. 2010;303(14):13921400.

39. Rahimi AR, Spertus JA, Reid KJ, Bernheim SM, Krumholz HM Financial barriers to health care and outcomes after acute myocardial infarction. JAMA. 2007;297(10): 1063-1072.

40. Lloyd-Jones DM, Hong Y, Labarthe D, et al. Defining and setting national goals for cardiovascular health promotion and disease reduction: the American Heart Association's strategic Impact Goal through 2020 and beyond. Circulation. 2010;121(4):586-613.

41. The Secretary's Advisory Committee on National Health Promotion and Disease Prevention for 2020. Department of Health and Human Services. 2008. Available at: https://www.healthypeople.gov/sites/default/files/ PhaseI_0.pdf. Accessed 26 April 2019.
42. Americans' Experiences with ACA Marketplace Coverage: Affordability and Provider Network Satisfaction. 2016. Available at: https://www. commonwealthfund.org/publications/issue-briefs/2016/jul/americansexperiences-aca-marketplace-coverage-affordability-and. Accessed 26 April 2019.

43. Global Burden of Cardiovascular Diseases C, Roth GA, Johnson Co, et al. The Burden of Cardiovascular Diseases Among US States, 19902016. JAMA Cardiol. 2018;3(5):375-389.

44. Collins SR, Gunja MZ, Doty MM, Bhupal H. First Look at Health Insurance Coverage in 2018 Finds ACA Gains Beginning to Reverse. The Commonwealth Fund. May 1, 2018. Available at: http://www. commonwealthfund.org/blog/2018/first-look-health-insurance-coverage-2018-finds-aca-gains-beginning-reverse?redirect_source=/publications/blog/2018/apr/health-coverage-erosion. Accessed 26 April 2019.

45. Congressional Budget Office. Federal Subsidies for Health Insurance Coverage for People under Age 65, 2017-2027. Washington DC: Congressional Budget Office, 2016. Available at: https://www.cbo.gov/ system/files?file=115th-congress-2017-2018/reports/53091-fshic.pdf. Accessed 26 April 2019.

Publisher's Note Springer Nature remains neutral with regard to jurisdictional claims in published maps and institutional affiliations. 